\title{
INELASTIC NEUTRON SCATTERING STUDY ON EG AND PEGS AS A FUNCTION OF THE DEGREE OF POLYMERIZATION
}

\author{
S. Magazù, G. Maisano, F. Migliardo \\ Dipartimento di Fisica and INFM, Università di Messina, PO Box 55, I-98166 Messina, Italy
}

(Received December 10, 2004)

\begin{abstract}
The present paper concerns with Inelastic Neutron Scattering (INS) results on Ethylene Glycol (EG) and PolyEthylene Glycols (PEGs) at different degree of polymerization. Significant spectral features of these systems are discussed in comparison with Raman spectroscopy findings. The results reveal a peculiar dependence on the degree of polymerization of the frequencies of the disordered longitudinal acoustic mode (D-LAM), which can account for the different bioprotectant effectiveness of PEGs at ambient and at very low temperature. The D-LAM behaviour as a function of the degree of polymerization as obtained by INS at low temperature is opposite to that observed by Raman spectroscopy at high temperature. These intriguing results are discussed in terms of inter and intra-molecular interactions within the framework of current theories.
\end{abstract}

Key words: inelastic neutron scattering, vibrational properties, polymers, disordered longitudinal acoustic mode.

PACS number(s): 61.12.Ex; 61.25.Hq; 63.50.Qx

\section{INTRODUCTION}

PolyEthylene Glycols (PEGs) are polymeric systems extensively investigated both theoretically and experimentally from 1960s [1-4]. In recent years new opportunities at the interface of polymer chemistry and biology have been explored. As an example, it has been demonstrated that PEG forming aqueous liquid-liquid twophase systems can be employed in the extractive separation of labile biomolecules such as proteins, offering mild conditions due to the low interfacial tension between the phases allowing small droplet size, large interfacial areas, efficient mixing under very gentle stirring and rapid partition. As an example [5], a series of ligands, generated by end-capping PEG polymers and amine-based dendrimers with the hapten 2,4-dinitrophenyl have been used to investigate the influence of polymeric backbone length, valency, and hapten presentation on the binding of mast cells. The results show that the length of the polymeric backbone significantly influences the potency of PEG-based inhibitors, therefore ligand features can be manipulated to control receptor occupation, aggregation, and ultimately, the cellular response [5].

Furthermore it has been found that PEG has unique advantages of interacting weakly with protein molecules and studies to characterize the rigidity of PEG of different molecular weights at very low temperature have been recently reported in literature [2]. Furthermore it has been found that PEG has unique advantages of interacting weakly with protein molecules and studies to characterize the strength of protein/protein interactions in the presence of PEG of different molecular weights and concentrations have been recently reported in literature [6], even if the molecular mechanisms underlying such an effect have not been clarified yet.

Li et al. [7] have investigated the effect of deionised water on salt containing tablets coated in PEG-containing silicone elastomer, and also the effects of water on free films, by observing that the osmotic force decreases with increasing levels of PEG content. The lower PEG levels allows water to be imbibed through the hydrated polymer; whilst the porosity resulting from the coating dissolving at higher levels of PEG content (20 to 40\%) allows the pressure to be relieved by the flow of $\mathrm{KCl}$. At higher loadings of PEG, the hydrated film was more porous and less resistant to outflow of salt. Hence, although the osmotic pumping increased (compared to the lower loading), trans-pore diffusion was the dominant release mechanism [7].

As is well known, degree of polymerization is a factor that strongly modifies the physical properties and hence the applications of PEGs. As an example, the compactization of a single DNA molecule in PEG at different degree of polymerization solution was investigated, by evidencing the dependence of critical value of PEG concentration at the point of DNA collapse on the degree of polymerization and on the concentration of lowmolecular salt [8].

This paper, which is addressed to the study of EG and PEGs disordered longitudinal acoustic modes (D-LAMs) that are connected with the lowest order intramolecular vibrations, reveal the effects of the degree of polymerization on the vibrational properties of these systems.

\section{EXPERIMENTAL SECTION}

Vibrational spectra of EG and PEGs at different degrees of polymerization, namely 4, 9, 13, corresponding to PEG 200, PEG 400 and PEG 600 (200, 400 and 600 being the molecular weights) have been collected by the indirect geometry time-of-flight (t.o.f.) spectrometer TOSCA at the ISIS Pulse Neutron Facility (DRAL, UK) [9] in the energy range $0 \div 4000 \mathrm{~cm}^{-1}(0 \div 500 \mathrm{meV})$ with 
the best results below $2000 \mathrm{~cm}^{-1}(250 \mathrm{meV})$. TOSCA's resolution (in the whole energy range of interest, the instrument provides very good energy resolution, about $\Delta E / E \approx 1.5 \div 2 \%$, which is comparable with optical techniques such as IR and Raman spectroscopies), combined with the high intensity of the ISIS source, allows to perform the study of the dynamics with high accuracy, reducing the background noise/signal ratio down to negligible for strongly scattering samples [9-10].

For the data treatment a small amount of flat background from the empty-cell measured at similar conditions was subtracted from the measured data. The measured INS data were transferred to the dynamical structure factor $S(Q, \omega)$ vs energy transfer by using a standard data treatment program. For what concerns the Debye-Waller factor that strongly influences the spectral intensity, its effect is reduced by collecting the INS spectra at low temperature. The multiple scattering contribution has been minimised by using a thin sample in order to obtain a scattering transmission from the sample $\geq 90 \%$.

For all the investigated hydrogenated samples, the measurement time was 12 hours for each run. For the sample preparation, thin walled aluminium cells have been used. The samples were cooled to $17 \mathrm{~K}$ by a liquid helium cryostat. Care was taken to obtain stable, clear and dust-free samples; ample time was allowed for equilibration.

From the structural point of view PEGs are polymers formed by chains of Ethylene Glycol (EG) or 1,2-ethanediol, 1,2-dihydroxyethane $\left(\mathrm{HOCH}_{2} \mathrm{CH}_{2} \mathrm{OH}\right)$, whose structure is described by the formula $\mathrm{HO}\left[-\mathrm{CH}_{2}-\right.$ $\left.\mathrm{CH}_{2}-\mathrm{O}-\right]_{n} \mathrm{H}$, where $n$ is the degree of polymerisation, e.g. the number of monomer units in chain.

\section{THEORETICAL BACKGROUND}

Inelastic Neutron Scattering provides a suitable probe for studies of vibrational dynamics in condensed materials, furnishing vibrational spectra which are different from Infrared (IR) and Raman spectroscopies due to various factors: i) for neutrons, no selection rule holds, because of the nuclear nature of the atomic scattering po- tential; ii) even if, as for IR and Raman spectra, in INS the frequencies are determined by the normal modes of vibration, the intensities depend, besides on the neutron scattering cross-section and on the moment transfer, on the amplitudes of vibrations; as a consequence, the band intensities in neutron spectroscopy allow to obtain precious information about the atomic displacements; iii) in INS spectra the low wavenumber vibrations give more intense bands than the high wavenumber ones; iv) finally due to the neutron sensitiveness to hydrogen vibrations, INS is particularly important in the study of hydrogen bonded systems.

From the formal point of view, the theoretical treatment of INS results moves by the well known expression for the dynamic structure factor:

$$
\begin{aligned}
& S_{\text {total }} \cong S(Q, \omega)_{\mathrm{vibr}}=\int_{-\infty}^{\infty} d t \exp (-i \omega t) \\
& \times \exp \left(-i Q^{2}\left\langle U(0)^{2}\right\rangle\right) \exp \left(-i Q^{2}\langle U(0) \cdot U(t)\rangle\right)
\end{aligned}
$$

Performing the Fourier transform from the time to the frequency domain it results that the time independent terms will include contributions from all frequencies whilst time dependent exponential terms will be specific to particular frequencies.

The usual one-phonon expression for high $\omega$ and low $T$ values reduces to [11]:

$$
S(Q, \omega)=\frac{Q^{2}: B_{\omega}}{3} \cdot \exp \left(-Q^{2}: \alpha_{\omega}\right)
$$

where $\alpha_{\omega}=\frac{1}{5}\left\{\frac{\operatorname{Tr} A}{3}+2 \frac{B_{\omega} \cdot A}{\operatorname{Tr} B_{\omega}}\right\}$ and $A=\sum_{\omega} B_{\omega}$. The observed intensity $S(Q, \omega)$ of a band at a frequency $\omega$ is function of the momentum transferred $Q$ (determined by spectrometer) and the vibrational amplitude $B_{\omega}$ of the hydrogen atoms that can be extracted.

Since the incoherent neutron scattering cross-section for hydrogen atom is much larger than those other atoms, for hydrogen containing materials, due to annihilation of $l$ and creation of $(k-l)$ excitations, we obtain [10-12]:

$$
\begin{aligned}
& S(Q, E)=\sum_{l, k} S_{l, k-l}(Q, E)=\sum_{l, k} \frac{\sigma_{H}^{\mathrm{inc}}}{4 \pi} \exp [-2 W(Q)] \\
& \times\left(\frac{\hbar^{2} Q^{2}}{2 m_{n}}\right)^{k} \int d \omega_{1} \ldots d \omega_{k} \frac{G\left(\omega_{1}\right) \ldots G\left(\omega_{k}\right)}{\omega_{1} \ldots \omega_{k}(k-l) ! l !} \times \prod_{i=l+1}^{k}\left[n\left(\omega_{i}\right)+1\right] \prod_{j=1}^{l} n\left(\omega_{j}\right) \times \delta\left(E-\sum_{i=l+1, k} \hbar \omega_{i}+\sum_{j=1, l} \hbar \omega_{j}\right)
\end{aligned}
$$


with $n(\omega)$ population Bose factor, $m_{n}$ neutron mass, $W(Q)$ Debye-Waller factor for hydrogen atom,

$W(Q)=\frac{1}{2}\left\langle(Q u)^{2}\right\rangle=\frac{\hbar^{2}}{12 m} \int \frac{Q^{2} G(\omega)}{\omega}[2 n(\omega)+1] d \omega$

and $G(\omega)$ generalized vibrational density of states for hydrogen atom.

\section{RESULTS AND DISCUSSION}

In Figure 1 INS spectrum of EG ranging from 25 up $2000 \mathrm{~cm}^{-1}$ is shown in comparison with that of ethene $\left(\mathrm{C}_{2} \mathrm{H}_{4}\right)$ [13]. As is evident from the figure, we note that EG presents a very structured spectrum in which several peaks are well distinguished in the three large bands $\left(\sim 25 \div 500 \mathrm{~cm}^{-1}, \sim 500 \div 1100 \mathrm{~cm}^{-1}\right.$, and $\left.\sim 1100 \div 2000 \mathrm{~cm}^{-1}\right)$. On the contrary, ethene shows just a bump up $\sim 820 \mathrm{~cm}^{-1}$ with some small peak and, separated from a small peak, a very large band in the region from $\sim 820$ to $\sim 2000 \mathrm{~cm}^{-1}$. Since the only difference between the two systems, EG and ethene, is that two $\mathrm{OH}$ groups are present in the EG molecule, where there is a competition between intermolecular and intramolecular hydrogen bonding interactions and furthermore $\mathrm{OH}$ interacting groups promote links among adjacent chains giving rise to many transient species $[14,15]$, we conclude that this is the reason why the vibrational modes of EG, in spite of the simplicity of the molecule, are very complex. In Table 1. a comparison of the INS frequencies of EG with IR and Raman frequencies is reported, by showing a good agreement of the vibrational band positions $[14,15]$.

\begin{tabular}{|c|c|c|}
\hline INS frequencies $\left(\mathbf{c m}^{-1}\right)$ & IR frequencies $\left(\mathbf{c m}^{-1}\right)$ & Raman frequencies $\left.\mathbf{( c m}^{-1}\right)$ \\
\hline 518 & 522 & \\
\hline 868 & 866 & 866 \\
\hline 928 & 883 & 1068 \\
\hline 1037 & 1042 & 1093 \\
\hline 1070 & 1087 & 1271 \\
\hline 1205 & 1204 & \\
\hline 1263 & 1253 & 1464 \\
\hline 1355 & 1331 & \\
\hline 1439 & 1457 & \\
\hline
\end{tabular}

Table 1. INS frequencies of EG compared with IR and Raman data.
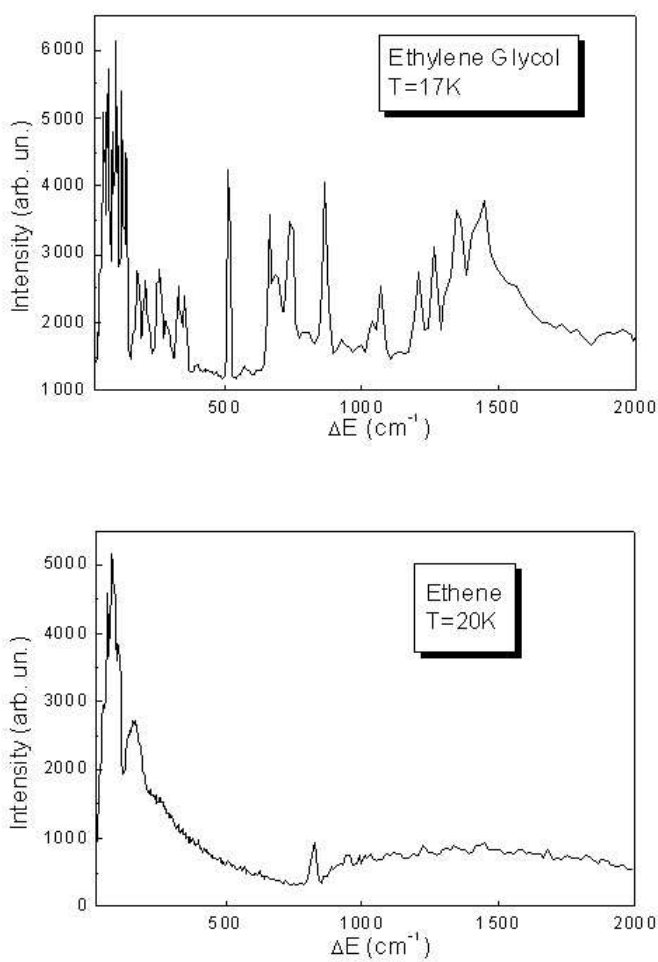

Fig. 1. INS spectra of EG and ethene $\left(\mathrm{C}_{2} \mathrm{H}_{4}\right)$ [13].
Let us focus the attention on the features of the EG, PEG 200, PEG 400 and PEG 600 INS spectra reported in Figure 2. In Table 2 vibrational frequencies of significant bands of the INS spectra of EG and PEGs are shown. In order to analyse the structural features of the spectra, we distinguish three regions: $\sim 40 \div 160 \mathrm{~cm}^{-1}$ (Region I), $\sim 160 \div 1100 \mathrm{~cm}^{-1}$ (Region II), and $\sim 1100 \div 2000 \mathrm{~cm}^{-1}$ (Region III).

\section{i) Region I: $\sim 40 \div 160 \mathrm{~cm}^{-1}$}

As previously described, in this region there are many important peaks linked to the D-LAM. As is known, D-LAM in Raman spectra of non-crystalline systems corresponds to low frequency broad polarized bands that replace the LAM bands $[15,16]$. These latter are characteristic of the crystalline state and in polymers are commonly attributed to a complex of contributions representing the polymer skeletal bending and stretching vibrations $[15,17]$.

As is evident from an inspection of Figure 3, where a comparison of INS spectra of EG and PEGs in the region of the D-LAM contributions are shown, and of Table 2 , contrarily to these findings at $T=17 \mathrm{~K}$ INS clearly indicated a shift to larger frequencies for the peaks. More specifically, at the beginning we performed a multiVoightian fitting procedure in order to assign the frequencies of the D-LAM peaks. We used three Voightian 
curves to fit all the spectra, by retaining that the three are the main peaks presents also in EG spectrum. This procedure furnishes the frequency values for the D-LAM peaks (D-LAM_1, D-LAM_2, D-LAM_3) reported in Table 2 and plotted in a graph D-LAM frequencies versus degree of polymerization $n$ in Figure 4.

\begin{tabular}{|c|c|c|c|}
\hline $\begin{array}{l}\text { EG } \\
\text { frequencies } \\
\left(\mathrm{cm}^{-1}\right)\end{array}$ & $\begin{array}{l}\text { PEG 200 } \\
\text { frequencies } \\
\left(\mathrm{cm}^{-1}\right)\end{array}$ & $\begin{array}{l}\text { PEG } 400 \\
\text { frequencies } \\
\left(\mathrm{cm}^{-1}\right)\end{array}$ & $\begin{array}{l}\text { PEG 600 } \\
\text { frequencies } \\
\left(\mathrm{cm}^{-1}\right)\end{array}$ \\
\hline 1439 & 1448 & 1501 & 1499 \\
\hline 1355 & 1341 & 1392 & 1406 \\
\hline 1263 & 1265 & 1312 & 1311 \\
\hline 1205 & 1223 & 1267 & 1270 \\
\hline 1070 & 1123 & 1162 & 1152 \\
\hline 1037 & 1060 & 1101 & 1097 \\
\hline 868 & 936 & 972 & 957 \\
\hline 740 & 883 & 911 & 908 \\
\hline 622 & 673 & 691 & 662 \\
\hline 577 & 574 & 597 & 581 \\
\hline 518 & 518 & 532 & 534 \\
\hline 356 & 360 & 372 & 357 \\
\hline 337 & 360 & 372 & 357 \\
\hline 329 & 360 & 372 & 357 \\
\hline 288 & 293 & 317 & 327 \\
\hline 263 & 237 & 244 & 245 \\
\hline 210 & 237 & 244 & 245 \\
\hline 185 & 192 & 200 & 202 \\
\hline 140 & 135 & 137 & 142 \\
\hline 125 & 129 & 131 & 131 \\
\hline 110 & 97 & 1103 & 104 \\
\hline 102 & 97 & 103 & 104 \\
\hline 93 & 97 & 103 & 104 \\
\hline 77 & 72 & 78 & 83 \\
\hline 67 & 72 & 78 & 83 \\
\hline 58 & 72 & 78 & 83 \\
\hline
\end{tabular}

Table 2. Vibrational frequencies of the INS spectra of EG and PEGs.

We can observe that in the spectrum of EG at $T=$ $17 \mathrm{~K}$ the $\mathrm{D}-\mathrm{LAM}$ contribution is present at very low frequency $\omega_{\mathrm{D}-\mathrm{LAM}} \approx 69 \mathrm{~cm}^{-1}$ in comparison with the Raman scattering results [14-16]. For what concerns PEGs, also if the general behaviour is opposite to that shown by Raman scattering (the peaks shift to larger frequencies) [14-16], from Figure 4 we note a similar plateau observed for $n \approx 9$. Secondly, we used another procedure and we fitted the D-LAM region with a Voightian by obtaining for the centroid a position frequency of 95, 91, 106 and $102 \mathrm{~cm}^{-1}$ for $n=1,4,9$ and 13 , respectively.

These results clearly indicate that, contrarily to what happens at room temperature, the rigidity of PEGs at very low temperatures increases with the polymerization degree. This finding justifies a different bioprotectant effectiveness of PEGs at very low and at room temperature.

ii) Region II: $\sim 160 \div 1100 \mathrm{~cm}^{-1}$

As regards this part of the spectra, from Table 2 and Figure 5 we can observe that, as in Region I, a general shift to larger values of frequency is maintained. The most important feature in this region is the very narrow and intense peak of EG at $\sim 520 \mathrm{~cm}^{-1}$ (in good agreement with that found in IR spectrum at $\sim 522 \mathrm{~cm}^{-1}$ ) that is still present in the PEGs spectra, but it is much broader, less intense, not shifted in PEG 200 spectrum, and shifted to $\sim 532 \mathrm{~cm}^{-1}$ and $\sim 534 \mathrm{~cm}^{-1}$ in PEG 400 and PEG 600 spectra, respectively.

In general, it is evident that the well defined peaks of EG, related to the complex vibrational modes of the monomer, are broader and broader and less and less sharp by increasing the degree of polymerization. In this region, in fact, we observe that PEG 600 presents the most "amorphous" behaviour in comparison with PEG 200 and PEG 400.

$$
\text { iii) Region III: } \sim 1100 \div 2000 \mathrm{~cm}^{-1}
$$

In this region shown in Figure 6 there are some interesting features to observe. In general the presence of a large bump that covers the whole region is common to all the investigated systems and it is broader for the PEGs than for EG. Furthermore, the bump and hence the peaks present in this part of the spectra are shift- 
ed to larger frequency values by increasing the degree of polymerization. Also in this case a plateau for $n \approx 9$ is reached. As a comparison, INS data existing in literature referring to polyethylene at $T=30 \mathrm{~K}$ [19] show a strong band at $\sim 1500 \mathrm{~cm}^{-1}$ that is attributed to the overlap of the $\mathrm{CH}_{2}$ scissors mode.
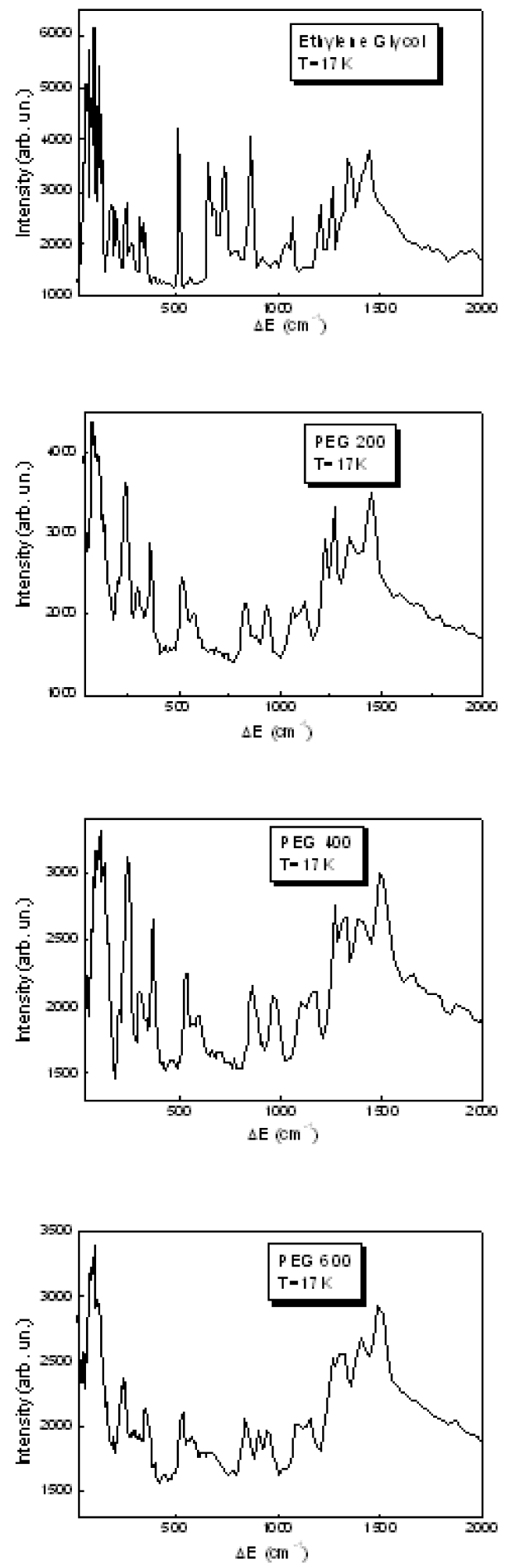

Fig. 2. EG, PEG 200, PEG 400 and PEG 600 INS spectra.
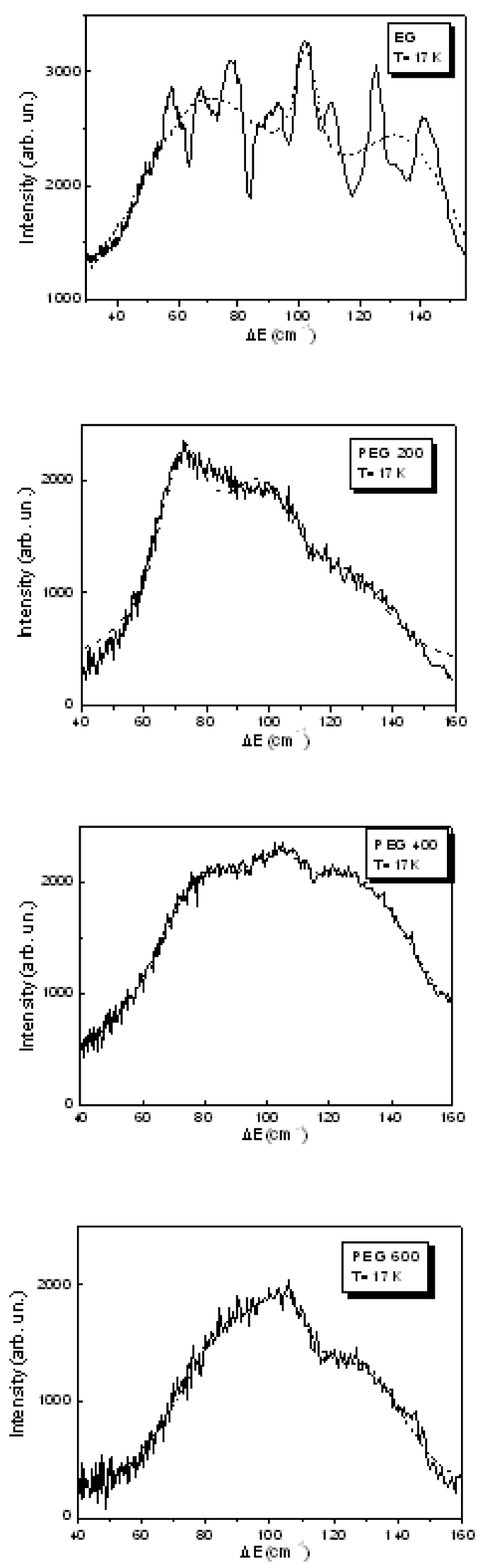

Fig. 3. Comparison of INS spectra of EG and PEGs in the region of the D-LAM contributions. 


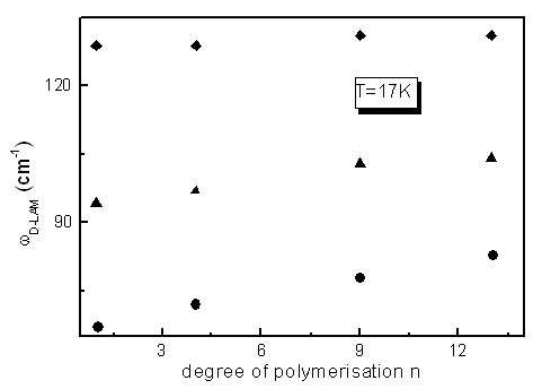

Fig. 4. INS D-LAM contribution as a function of degree of polymerization at $T=17 \mathrm{~K}$.
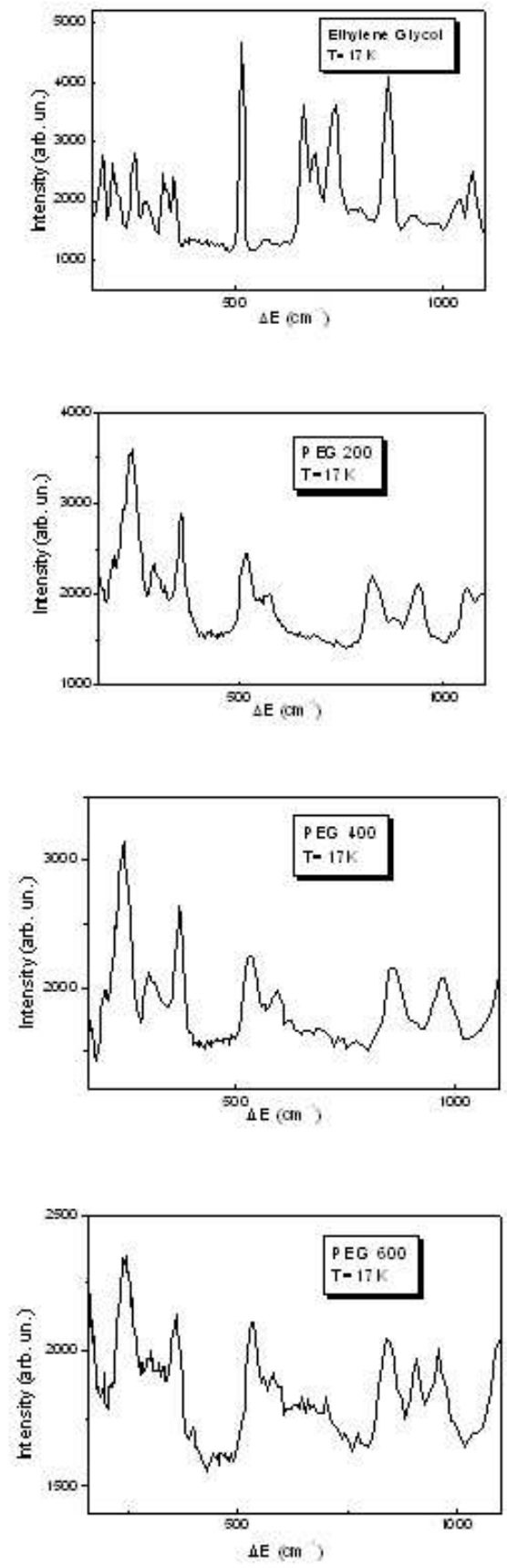

Fig. 5. Comparison of INS spectra of EG and PEGs in the $160 \div 1100 \mathrm{~cm}^{-1}$ region.
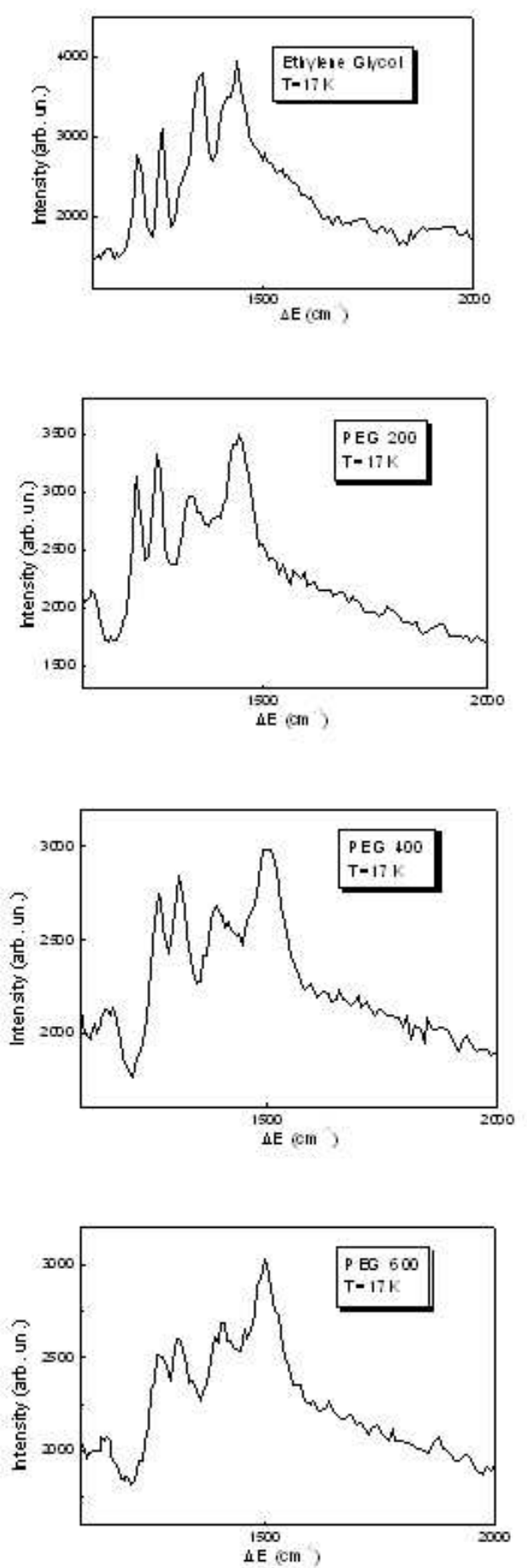

Fig. 6. Comparison of INS spectra of EG and PEGs in the $1100 \div 2000 \mathrm{~cm}^{-1}$ region.

By analyzing the spectra in more detail, we note that the two peaks present in EG spectrum at $\sim 1205$ and $\sim 1263 \mathrm{~cm}^{-1}$ are more intense in the PEGs spectra, where it is also noticeable that they are less and less distinct and tend to merge into a single peak increasing the degree of polymerization. The other two peaks at $\sim 1355$ and $\sim 1439 \mathrm{~cm}^{-1}$ also increase in intensity for the PEGs spectra; in particular their relative intensities, that are comparable in EG, change strongly and the second peak becomes much more important that the first one as a consequence of a degree of the increase polymerization. 


\section{CONCLUSIONS}

In this paper INS findings on Ethylene Glycol (EG) and PolyEthylene Glycols (PEGs) at different degrees of polymerization are shown. In particular, the attention was focused on the low frequency region of the spectra, where D-LAM contributions are present. The obtained results are summarized in the following points:

1. Contrarily of the Raman Scattering, results obtained at higher temperatures [15], INS allows to observe a shift to higher values of frequency for the D-LAM peaks and a similar plateau for $n \approx 9$.

2. By performing a multi-Voightian fitting procedure in order to assign the frequencies of the D-LAM peaks, we note that in the spectrum of EG at $T=17 \mathrm{~K}$ the D-LAM contribution is present at a very low frequency of $\omega_{\mathrm{D}-\mathrm{LAM}} \approx 69 \mathrm{~cm}^{-1}$ in comparison with that evaluated by Raman scattering at $T=233 \mathrm{~K}[15]$.
3. For what concerns the spectral region $\sim 160 \div 1100 \mathrm{~cm}^{-1}$, it is evident that a general shift to larger values of frequency with degree of polymerization increasing is maintained and that the well defined peaks of EG, related to the complex vibrational modes of the monomer, are broader and broader and less and less sharp by increasing the degree of polymerization. In this region, in fact, we observe that PEG 600 presents the most "amorphous" behaviour in comparison with PEG 200 and PEG 400.

4. The region $\sim 1100 \div 2000 \mathrm{~cm}^{-1}$ of the spectra shows the presence of a large bump that covers the whole region and that is common to all the investigated systems. Furthermore, the bump and hence the peaks present in this part of the spectra are shifted to larger frequency values by increasing the degree of polymerization. Also in this case a plateau for $n \approx 9$ is reached.
[1] D. R. Jones, C. H. Wang, J. Chem. Phys. 66, 1659 (1977).

[2] S. D. Druger, M. A. Ratner, A. Nitzan, Phys. Rev. B 31, 3939 (1985).

[3] C. Morrison, Biophys. J. 64,1063 (1993).

[4] D. M. Bubb, M. R. Papantonakis, B. Toftmann, J. S. Horwitz, R. A. McGill, D. B. Chrisey, R. F. Haglund, J. Appl. Phys. 91, 9809 (2002).

[5] G. Coates, LSNM Symposium Abstract (2001).

[6] A. M. Kulkarni, A. P. Chatterjee, K. S. Schweizer, J. Chem. Phys. 113, 9863 (2000).

[7] L. C. Li, G. E. Peck, Drug Dev. Ind. Pharm. 15, 1943 (1989).

[8] V. V. Vasilevskaya, A. R. Khokhlov, Y. Matsuzawa, K. Yoshikawa, J. Chem. Phys. 102, 1193 (1985).

[9] D. Colognesi, S. F. Parker, The TOSCA Manual, Rutherford Appleton Laboratory UK (1999).

[10] D. K. Breitinger, J. Mohr, D. Colognesi, S. F. Parker, H. Schukow, R. G. Schwab, J. Mol. Struct. 563, 377
(2001).

[11] A. I. Kolesnikov, J. C. Li, S. F. Parker, R. S. Eccleston, C.-K. Loong, Phys. Rev. B 59, 3569 (1999).

[12] J. C. Li, J. Chem. Phys. 105, 6733 (1996).

[13] TOSCA database, www.isis.rl.ac.uk and references therein.

[14] V. Crupi, M. P. Jannelli, S. Magazù, G. Maisano, D. Majolino, P. Migliardo, D. Sirna, Mol. Phys. 84, 645 (1995).

[15] C. Branca, S. Magazù, G. Maisano, P. Migliardo, V. Villari, J. Phys.: Condens. Matter 10, 10141 (1998).

[16] R. G. Snyder, H. L. Strauss, J. Chem. Phys. 87, 3779 (1987).

[17] H. Nishide, M. Ohyanagi, O. Okada, E. Tsuchida, Macromolecules, 19, 496 (1986).

[18] R. G. Snyder, J. Chem. Phys. 76, 3921 (1982).

[19] S. F. Parker, Inelastic Neutron Scattering of Polymers, in Applications of Neutrons to Soft Condensed Matter, (Gordon and Breach, Amsterdam, 2000).

\title{
НЕЕЛАСТИЧНЕ НЕЙТРОННЕ РОЗСІЮВАННЯ НА ЕТИЛЕН-ГЛІКОЛІ (ЕГ) ТА ПОЛІЕТИЛЕН-ГЛІКОЛЯХ (ПЕГ) ЯК ФУНКЦІЯ СТУПЕНЯ ПОЛІМЕРИЗАЦЇ̈
}

\author{
С. Магацу, Г. Маізано, Ф. Мільярдо \\ Університет Мессіни, фізичний факультет, РО Вох 55, Мессіна, I-98166, Італія
}

\begin{abstract}
У статті висвітлено результати нееластичного нейтронного розсіювання на етилен-гліколі (ЕГ) та поліетилен-гліколі (ПЕГ) при різному ступені полімеризації. Обговорено суттєві спектральні риси цих систем порівняно з результатами раманівської спектроскопії. Наші результати показують цікаву залежність від ступеня полімеризації частот невпорядкованої поздовжньої акустичної моди (D-LAM). Цей ефект пояснює різну біозахисну ефективність поліетилен-гліколів при температурі середовища та при дуже низьких температурах. Поведінка D-LAM як функції ступеня полімеризації, отримана на підставі нееластичного нейтронного розсіювання при низькій температурі, протилежна до поведінки, спостережуваної в раманівській спектроскопії при високій температурі. Ці нові перспективні результати оцінено в термінах між- та внутрішньомолекулярної взаємодії з погляду сучасних теорій.
\end{abstract}

